\title{
Global Pollution: How Much Is Too Much?
}

\author{
Jack T. Trevors • Milton H. Saier Jr
}

Published online: 23 October 2009

(C) The Author(s) 2009. This article is published with open access at Springerlink.com

All people on our blue planet should have already asked themselves four questions: (1) How much global pollution can our planet tolerate and still maintain its biosphere sustainably? (2) Can humanity survive the predicted global climate change disaster with any quality of life? (3) What are the principal causes of our failure to retain a healthy life-supporting biosphere? and (4) What needs to be done to reverse the damage that has already been done by our species?

There is already more pollution on our planet than we can cope with. This is most evident from the estimated rates of species extinction which are up roughly 10,000-100,000-fold due to human activities. All experts agree: We have too many people, consuming too many resources, producing too much heat and pollution in our singular common biosphere. We do not need more economic growth; we do not need more globalization; we cannot tolerate more consumption of resources, and we cannot continue to

J. T. Trevors $(\bowtie)$

School of Environmental Sciences, University of Guelph, Guelph, ON N1G 2W1, Canada

e-mail: jtrevors@uoguelph.ca

M. H. Saier Jr $(\bowtie)$

Division of Biological Sciences, University of California, San Diego,

La Jolla, CA 92093-0116, USA

e-mail: msaier@ucsd.edu manufacture totally useless consumer products. In fact, we are forced to come to the conclusion that, to save the Earth for humanity, capitalism for profit as the primary driving force for achievement and personal well-being must be abandoned. Most importantly, our present excessive population must be drastically reduced as a prerequisite for long-term human survival.

Dennis Dimick, Executive Editor for National Geographic Magazine; Emily Douglas, Web Editor for The Nation; and Andrew Revkin, Environmental Reporter for The New York Times on October 14th noted that our current policy makers "will be missing the most important piece of the sustainability puzzle if global health and population dynamics are ignored." Ignoring these issues would mean "not only overlooking potential solutions but also multiplying the suffering of those already most at risk." They go on to suggest that "population growth's effect on climate change lacks nuance." After all, reporters writing about global population-environment connections face significant barriers to in-depth coverage, especially from the fanatical right wing of America and other nationalistic groups uninterested in the plight of others around the globe. Contrary to the teachings of their prophets, these people, including many religious zealots, refuse to acknowledge the global crisis we face. It seems clear that science needs to trump irrational thought if real progress is to be made.

What are the challenges facing science and environmental reporters as they prepare to cover 
"the story of our time"? Their challenges must deal with irrationality, misconception, and false propaganda. To counteract these intentionally misleading efforts, the forthcoming international 2009 Behavior, Energy and Climate Change Conference (BECC) has been planned. It will focus on accelerating our transition to an energy-efficient and low-carbon economy through an improved understanding and application of social and behavioral research insights. This conference will be held on November $15-18,2009$ in Washington, DC. Its purpose is to catalyze collaboration across the arenas of government, business, and research and to share the results of recent research efforts in order to promote the goal of achieving viable solutions to our environmental crisis. The organizers contend that there is no time to lose in meeting long-term energy targets designed to drastically reduce carbon dioxide emissions and the dissemination of other pollutants. They have boldly acknowledged that we are likely to accomplish little if human overpopulation is not included as a key focus of discussion at the conference and as a top priority in our cooperative efforts to achieve sustainability. Consequently, in contrast to many earlier meetings, this all-important topic will be on the agenda.

The 2009 BECC will bring together a diverse group of policy makers, energy experts, social scientists, and communicators to discuss the social and behavioral changes that will be required to reduce energy use. This will in part be achieved through the adoption and application of more energy-efficient technologies and energy conservation activities. However, it is recognized that major lifestyle changes can lead to a more sustainable world, particularly through education and reduced human population. Through lifestyle changes, it is hoped that wastage can be minimized while human fertility can be controlled. The latter can only be achieved though the provision of international family planning services, providing women with the opportunity to control their own reproductive behavior. It is eminently clear that only when our population is in decline will we be able to approach the achievement of real sustainability.

How much consumption and pollution, caused by our excessive human population, do we collectively need in order to collapse our biosphere? No one can quantitate pollution or its consequences exactly because both are complex with many contributing factors. These factors will have different effects on different environmental parameters. The more global warming, the more pollution in the biosphere, the more oceanic acidification, and the more acid rain, the more we will lose biospheric diversity. We must take very seriously the available statistics that point to environmental destruction and species extinction as contributing causes of the potential loss of our precarious human civilizations. Does any rational individual think we can tolerate more environmental loss? Certainly not. Do even the most irrational people, unconcerned about the environmental plight of mankind and the possible loss of human society, think we need more? Put this way, maybe even they would be on the fence.

We do not need more manufactured consumer products. They are not a significant part of human society or environmental health. They do not contribute to the educational needs of the world's populations. They reduce agricultural productivity and endanger our food security. They do not provide potable water or facilitate waste management. They do not provide transportation or communication services. They do not generate energy. In fact, they do nothing to help solve the many problems that our excessive human population is creating at everincreasing rates. They endanger human and biospheric health; they increase carbon dioxide production and contribute to other forms of pollution; they use water supplies that are direly needed to maintain the biosphere upon which we all depend. Consumerism is simply not the answer. Reducing the human population and exercising more judicious choice of consumption are beyond a doubt the most important goals that could allow the continuance of human civilization as we know it. The equation is simple really: reduce consumption AND the human population, humanely, and we have a chance.

How much global pollution will be required before ALL individuals on Earth recognize the dire consequences? If all world citizens were well educated, the most serious issues facing mankind would have been seriously addressed years ago, and solutions to some of them would already have been found and implemented. No rational person can think that 6.8 billion humans with skewed consumption by affluent 
nations can continue to grow and consume. No sensitive empathetic individual can feel content when one to two billion humans do not have their basic needs met.

If 6.8 billion humans and $390 \mathrm{ppm}$ of atmospheric carbon dioxide are not excessive, then shudder at even the most conservative estimates for the future. Can the concentration of carbon dioxide be lowered? Can the human population be reduced by several billion without tremendous suffering and premature death? Reduced consumption and the provision of universal birth control would be a good target and our best investment. The alternative? You guessed it.

Open Access This article is distributed under the terms of the Creative Commons Attribution Noncommercial License which permits any noncommercial use, distribution, and reproduction in any medium, provided the original author(s) and source are credited. 